\title{
Host-plant patch qualities and presence of a likely competitor species affect the distribution and abundance of a rare British moth, Cucullia lychnitis
}

\author{
Callum J. Macgregor ${ }^{1,2,3} \cdot$ Daniel J. Hoare $^{2} \cdot$ Mark S. Parsons $^{2} \cdot$ Owen T. Lewis $^{3}$
}

Received: 8 December 2016 / Accepted: 15 February 2017 / Published online: 28 February 2017

(C) The Author(s) 2017. This article is published with open access at Springerlink.com

\begin{abstract}
Understanding the environmental factors that affect the distribution and abundance of rare and threatened species can help identify priority sites for conservation action such as habitat management. The moth Cucullia lychnitis is identified in UK legislation as a priority species for conservation. Its conspicuous larvae feed on a patchily distributed host plant Verbascum nigrum, but are entirely absent from some host plant patches within the species' range. Environmental variability among patches was investigated to understand factors affecting (i) patch occupancy by $C$. lychnitis and (ii) abundance of $C$. lychnitis, where present. Occupancy of individual $V$. nigrum plants within occupied patches was also investigated. The likelihood of patch occupancy increased with patch size, and decreased with patch isolation. Abundance of $C$. lychnitis was negatively correlated with patch isolation and with abundance of the weevil Cionus nigritarsis, which exploits the same host plant and may be a competitor. Within occupied patches, larvae of $C$. lychnitis were significantly more likely to be found on taller plants with more flower spikes; such plants are typical of established rather than newly-created patches. These results may help to guide efforts to conserve
\end{abstract}

Electronic supplementary material The online version of this article (doi:)10.1007/s10841-017-9963-5 contains supplementary material, which is available to authorized users.

Callum J. Macgregor

callumjmacgregor@gmail.com

1 School of Biology, Newcastle University, Newcastle upon Tyne NE1 7RU, UK

2 Butterfly Conservation, Manor Yard, East Lulworth, Wareham, Dorset BH20 5QP, UK

3 Department of Zoology, University of Oxford, South Parks Road, Oxford OX1 3PS, UK
C. lychnitis, highlighting the importance of habitat connectivity and indicating potential management actions to promote features positively associated with larval incidence and abundance.

Keywords Conservation - Interspecific competition · Lepidoptera $\cdot$ Metapopulations $\cdot$ Road verges $\cdot$ Spatial ecology

\section{Introduction}

Reversing declines in biodiversity will often require conservation action targeted at species that are in decline. In the United Kingdom (UK), for example, legislation identifies 2,888 species considered to be "of principal importance for the purpose of conserving biodiversity" which are priorities for conservation [Natural Environment and Rural Communities (NERC) Act 2006]. Among a number of Lepidoptera species on this list is the Striped Lychnis Cucullia lychnitis Rambur (Lepidoptera: Noctuidae; listed under its former name Shargacucullia lychnitis). This species occurs across much of Europe, but in the UK is restricted to two centres of population in central southern England, one in Oxfordshire, Berkshire and Buckinghamshire, and one slightly further south in Hampshire and West Sussex (Fig. 1). This restricted range is reported to represent a considerable contraction of the species' historic range, with the species historically recorded as far afield as Gloucestershire in the west of England and Essex in the east (Heath and Emmet 1983). Its declining range size accounts for its selection as a Priority Species in the NERC Act (2006), and C. lychnitis appears to have continued to decline since being listed (Rosenthal 2011). 


\subsection{Striped Lychnis (Cucullia lychnitis)}

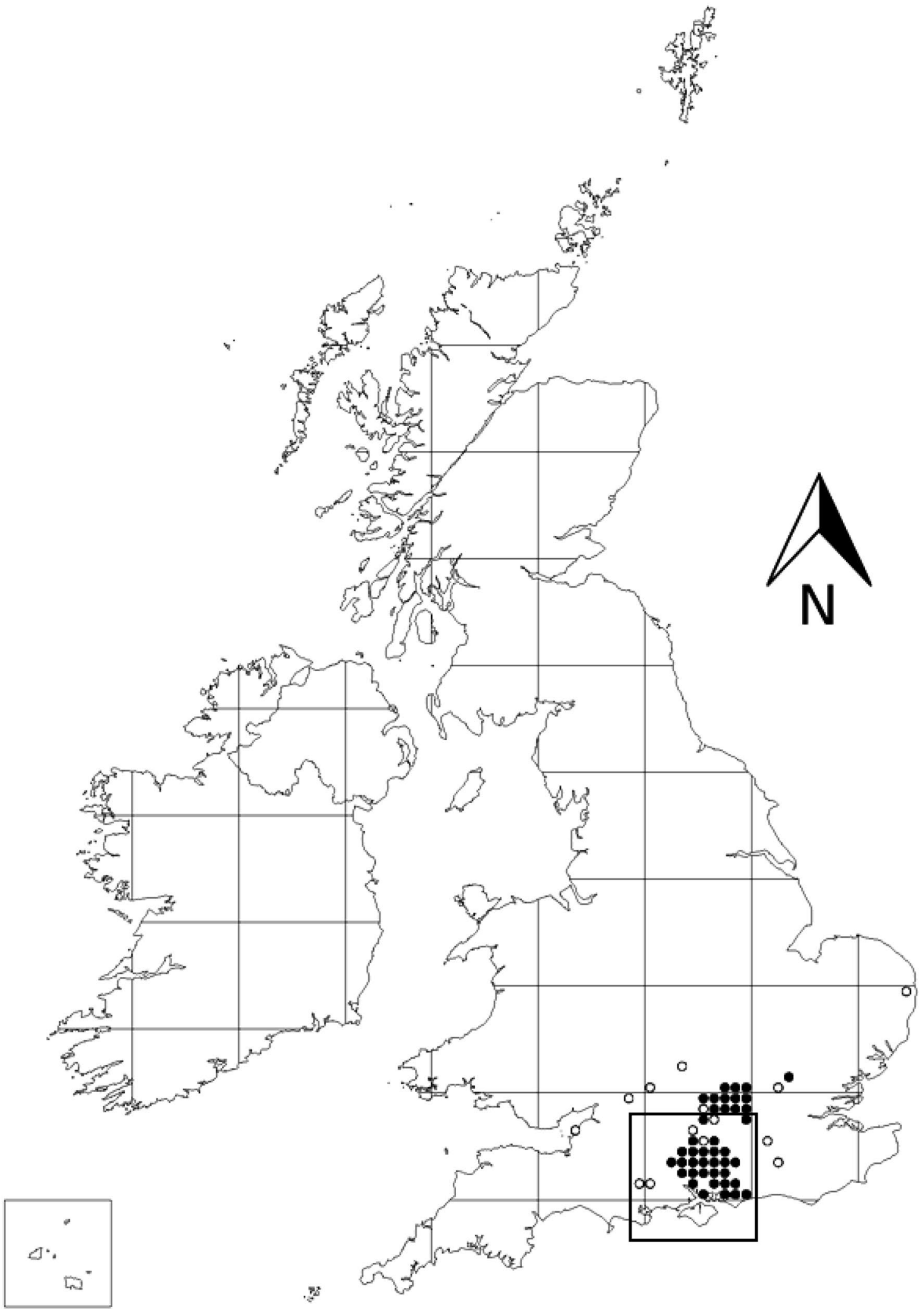


4Fig. 1 Distribution of Cucullia lychnitis in the UK. Black circles represent $10 \mathrm{~km}$ grid squares with records of $C$. lychnitis (including both larvae and adults) from 2000 onwards, white circles represent additional grid squares with records of C. lychnitis from before 2000. Box indicates the area displayed in Fig. 2. Data were provided from the National Moth Recording Scheme, courtesy of Butterfly Conservation. Map produced by MapMate ${ }^{\mathrm{TM}}$ using Digital Map Data ${ }^{\odot}$ HarperCollins-Bartholomew 2013

Adult $C$. lychnitis are nocturnal, and are active between May and early August, laying eggs throughout this period. Eggs are laid primarily on the leaves of Dark Mullein Verbascum nigrum L. (Scrophulariaceae), with occasional records from other Verbascum species and Scrophularia species (Heath and Emmet 1983). Larvae feed on the flowers and developing seedheads of the host plant before pupating on or just under the soil surface. V. nigrum also has a restricted range within the UK; it is a ruderal species (Fenner 1978), readily colonising disturbed soils and short turf, preferring calcareous soils and frequenting road verges, hedge banks and grassy places (Preston et al. 2002). Thus, mown road verges (if appropriately managed) are potentially an important habitat for this species and so for C. lychnitis. V. nigrum is biennial, but can persist for several years, and occurs in distinct patches varying in size from single plants to several hundreds. The NERC Act (2006) identifies host-plant availability as the key target for conserving $C$. lychnitis; however, within the range of $C$. lychnitis, larvae of the moth can be found readily in some patches of $V$. nigrum but are absent from others (Heath and Emmet 1983).

An important first step to conserve a species is an understanding of the biotic and abiotic variables that influence its distribution and abundance (Thomas et al. 2010). For C. lychnitis such information will be informative about the factors shaping the species' current distribution and potential future changes in distribution, as well as helping to inform habitat management strategies. Studies investigating the incidence and abundance of butterfly species within fragmented landscapes are frequent (Thomas et al. 1992; Hanski et al. 1994; Hill et al. 1996), but fewer such studies have focused on moths. Three specific questions were addressed: (1) Which ecological variables influence the occupancy of $V$. nigrum patches by larvae of $C$. lychnitis? (2) Which variables influence the abundance of $C$. lychnitis larvae within occupied patches? (3) Which variables influence the use of individual $V$. nigrum plants within occupied patches?

\section{Materials and methods}

\section{Locating and identifying patches}

Data were obtained detailing presence/absence of $V$. nigrum at tetrad resolution $(2 \mathrm{~km} \times 2 \mathrm{~km}$ squares $)$ from the Botanical Society of the British Isles (BSBI) Maps Scheme, covering an area that included and surrounded the range of the southern English population of C. lychnitis. Tetrads in this area with $V$. nigrum present were further divided into two categories, those with and without records of $C$. lychnitis larvae during two extensive recent surveys (Hoare and Thomas 2006; Rosenthal 2011). Tetrads to be searched were randomly selected from each category in equal numbers. Tetrads were searched over a 6-week survey period from mid-July to early September 2012, timed to encompass the entire duration of the larval season.

Flower spikes of $V$. nigrum are tall (typically around $1 \mathrm{~m}$ ), bright yellow and highly conspicuous. This, along with the plant's association with road verges, meant it was possible to locate the plant by systematically searching all road verges within a selected tetrad. A small number of occupied patches were known from previous surveys to exist away from roadsides; however, searching the entire accessible area of each tetrad would have been prohibitively labour-intensive and might have limited the total number of tetrads that could searched over the course of the survey. As the vast majority of known patches were road verges, and as these have been shown to be preferred to other habitats by C. lychnitis (Hall 2010), it was decided that limiting searching effort to road verges would be a suitable, and readily repeatable, method.

Anywhere that $V$. nigrum was located was considered a patch. Patch boundaries were defined by the criterion that no further $V$. nigrum could be found during a 1-min search on foot in every possible direction; the ease with which $V$. nigrum flower spikes can be spotted allowed a distance of several tens of metres to be searched within a minute. Such distances have been accepted as sufficient to distinguish patches in previous studies of lepidopterans using patch isolation as an explanatory variable (Hanski et al. 1994). In all but a very few cases, patches were separated by considerably greater distances than the threshold minimum, and no patches were separated by less than $100 \mathrm{~m}$. Once a patch was identified, a range of variables were recorded, as described below.

\section{Number of Cucullia lychnitis larvae}

All flower spikes at each patch were comprehensively searched, and the total number of $C$. lychnitis larvae within the patch counted. Larvae were only readily located at third instar or later, primarily due to size, and indeed younger larvae were only ever located after larvae at third instar or older had already been observed at a patch. In addition, it was expected that larval abundance within a patch might vary over the course of the larval season (including frequency of more easily-located older larvae), and that it would not be possible to survey all patches simultaneously 
(nor would this be a perfect control for any phenological variation between patches). Therefore, it was decided that all patches would be revisited at least once over the course of the 6-week survey period, and the greatest number of larvae found at any one visit to each patch used in analyses looking at abundance of larvae. In addition, the number of flower spikes with larvae on them was recorded, although in most cases this differed little from the total number of larvae as it was rare to observe more than one larva on a flower spike.

\section{Verbascum nigrum abundance and density}

Patch size was estimated as the total abundance of $V$. nigrum flower spikes present, in accordance with previous surveys of $C$. lychnitis (Hoare and Thomas 2006; Rosenthal 2011). Most plants have a single flower spike, although some older plants may have several; however, due to the difficulty of separating plants (especially in long or dense swards), the number of individual flower spikes is accepted as a reasonable approximation for host plant abundance, and so every flower spike was counted even where it was clear that they belonged to the same plant. As a second measure of patch size, host plant density within a patch was estimated using a DAFOR scale (Fowler et al. 2013). Each patch was to be categorised into one of five categories by average density of $V$. nigrum across the full patch area (for category definitions, see Online Resource 1.1). However, no road verge patches were located fitting the 'Dominant' or 'Abundant' categories, meaning that $V$. nigrum in all patches was classified as being 'Frequent', 'Occasional' or 'Rare'.

\section{Location and patch isolation}

A GPS unit was used to record the six-figure grid reference (accurate to $100 \mathrm{~m}$ ) of the approximate centre of each patch (Winfree et al. 2005). This was then used to plot the precise location of patches into Google Earth. Isolation from all patches of $V$. nigrum, as well as just those occupied by $C$. lychnitis, was considered. Four location-specific measures of patch isolation were examined. Firstly, the number of tetrads immediately surrounding a patch without $V$. nigrum records in the BSBI data was taken as a broad-brush measure of isolation; this provided each patch with a tetrad isolation score from 0 (not isolated) to 8 (very isolated). Secondly and thirdly, two variations on nearest neighbour (NN) methods were used; the absolute distance (in $\mathrm{km}$ ) between patch grid references, calculated using the Ruler function of Google Earth, and the smoothed NN distance, calculated as the average distance in kilometres to each patch's three NNs. Using a mean distance to several neighbours reduced the tendency for paired but otherwise isolated patches to be recorded as having low isolation. Finally, the absolute distance in kilometres from each patch to the nearest patch occupied by $C$. lychnitis larvae was measured, again using Google Earth. As only a sample of tetrads was surveyed, rather than the entire landscape, these measures may be affected by neighbours of some patches being missed. However, the geographically random sampling procedure should ensure that analyses were unbiased.

\section{Sward height}

A standard drop disc (as described in Stewart et al. 2001: $30 \mathrm{~cm}$ in diameter and weighing $200 \mathrm{~g}$, to be dropped from a height of $1 \mathrm{~m}$ ) was used to measure sward height. Sward height was measured in five arbitrarily selected locations within $2 \mathrm{~m}$ of $V$. nigrum plants at each patch, and a mean value taken for the patch.

\section{Wind shelter and insolation}

Wind shelter at each patch was categorised by an estimate of the proportion of the patch periphery protected by obstacles to wind, which included hedges, woodlands, buildings or similar. For category definitions, see Online Resource 1.2. Slope was measured using a clinometer and a pair of $2 \mathrm{~m}$ ranging poles at $10 \mathrm{~m}$ distance, and aspect using a standard magnetic compass. However, the vast majority of patches had a slope value close to zero (and thus no discernible aspect); therefore, these variables were not analysed further.

\section{Cionus nigritarsis abundance}

Cionus nigritarsis Reitter (Coleoptera: Curculionidae) also feeds on $V$. nigrum at the larval stage (Morris 2002; Sõber et al. 2010). Larvae of $C$. nigritarsis can typically be located on $V$. nigrum at an earlier date than C. lychnitis larvae, and therefore likely emerge and begin feeding slightly earlier, potentially impacting larval survival through interspecific competition. Abundance of $C$. nigritarsis was estimated using an adaptation of the DAFOR scale (Fowler et al. 2013). The category boundaries used were altered to be suitable to estimate the abundance of the weevil rather than of a plant, and a sixth available category ('None') was added for patches where no larvae of $C$. nigritarsis were observed (for category definitions, see Online Resource 1.3).

\section{Within-patch variables}

At the majority of patches where C. lychnitis larvae were present, the number of flower spikes and height of the tallest flower spike was recorded for each plant, along 
with whether larvae were present on each plant. Flower spike height was measured using two $1 \mathrm{~m}$ rulers, held end-to-end where flower spikes were taller than $1 \mathrm{~m}$. Multiple flower spikes on a single plant could usually be identified, as flower spikes branched above ground level in the sward. These measurements were not taken at patches with only one or two larvae and a large number of $V$. nigrum plants, as it was considered that patterns deduced from such low densities of $C$. lychnitis might not be reliable. Several patches were revisited on multiple occasions, and larvae were at no time observed to move between plants, although it is possible that this could occur.

\section{Statistical analyses}

Generalized linear models (GLMs) were constructed to test for differences in C. lychnitis abundance and patch- and plant-level occupancy attributable to the ecological variables described above. Significance of effects within models was tested using likelihood ratio tests.

For each patch-level dependent variable (patch occupancy by $C$. lychnitis, abundance of $C$. lychnitis, and density of $C$. nigritarsis), we first selected variables for patch size and isolation for use in subsequent models by constructing models separately for each recorded measure for each variable. The variables used in the models with the lowest Akaike information criterion (AIC) values were selected for subsequent analysis in each case. A global model was then constructed with the two selected variables alongside mean sward height, $C$. nigritarsis density (except when this was analysed as a dependent variable) and wind shelter. Finally, this was narrowed down to the final model by removing variables in a stepwise fashion according to AIC values until no variable could be removed to reduce the AIC value further. For the plant-level occupancy analysis, plant height and number of flower spikes were included as fixed effects and patch as a random effect in a generalized linear mixed-effects model (GLMM). Significance of variables in all final models was tested using a likelihood ratio test. In cases where outliers were suspected to have influenced the results, the steps above were repeated with potential outliers removed; if this did not change the outcome, the original model (with potential outliers included) was used.

Data were analysed and figures plotted using $\mathrm{R}$ version 3.3.2 (R Core Team 2016). GLMs and GLMMs were constructed using the lme4 package (Bates et al. 2015). Figures were plotted using the packages ggplot2 (Wickham 2009) and ggmap (Kahle and Wickham 2013). R scripts used in analysis and plotting of figures are included in RMarkdown format in Online Resource 2.

\section{Results}

A total of 47 patches were identified with $V$. nigrum present (Fig. 2); larvae of C. lychnitis were located at 12 of these (26\%). A minimum of 84 C. lychnitis larvae were identified across those 12 patches; the maximum located in a single visit to 1 patch was 20 , and 4 patches had only 1 larva at each visit. A total of 203 individual $V$. nigrum plants were measured across seven occupied sites.

Patch-level occupancy was significantly affected by both patch size, measured as V. nigrum abundance (Table 1; $\left.\chi^{2}=22.76, P<0.001\right)$, and patch isolation, measured as mean NN distance (Table $1 ; \chi^{2}=11.15, P<0.001$ ). Larvae of $C$. lychnitis were most likely to occupy patches that were close to other patches and had higher abundances of V. nigrum (Fig. 3).

Abundance of $C$. lychnitis larvae at patches where they were present was significantly affected by both $C$. nigritarsis larval density (Table $1 ; \chi^{2}=47.11, P<0.001$ ), and patch isolation, measured as mean NN distance (Table 1; $\left.\chi^{2}=4.97, P=0.026\right)$. Larvae of $C$. lychnitis were most abundant in patches with low densities of $C$. nigritarsis (Fig. 4) and that were more isolated from other patches (Fig. 5). Neither the direction nor the significance of these effects was changed by the removal of an apparent outlier (the patch with simultaneously the highest abundance of $C$. lychnitis and the greatest isolation) from the dataset (Table 1).

Plant-level occupancy was significantly affected by both plant height (Table $1 ; \chi^{2}=7.05, P=0.008$ ) and number of flower spikes (Table $1 ; \chi^{2}=54.76, P<0.001$ ). Larvae of C. lychnitis were most likely to occupy plants that were tall and had many flower spikes (Fig. 6), indicating a preference for plants in their second year or older.

Density of $C$. nigritarsis larvae between patches was significantly affected by both patch size, measured as $V$. nigrum abundance (Table $1 ; \chi^{2}=15.49, P<0.001$ ), and patch isolation, measured as mean NN distance (Table 1; $\left.\chi^{2}=4.56, P=0.033\right)$. Larvae of $C$. nigritarsis were at higher density in patches that were close to other patches and had high abundances of V. nigrum.

\section{Discussion}

Our results reveal that the success of $C$. lychnitis is affected by different abiotic and biotic variables at different scales. At a landscape scale, larvae of $C$. lychnitis were most likely to occupy patches with abundant $V$. nigrum, and patches that were close to several other patches, regardless of whether or not these patches were occupied by $C$. lychnitis (Fig. 3). This pattern reflects that found by Thomas et al. (1992) in four species of UK butterflies, but is less well 


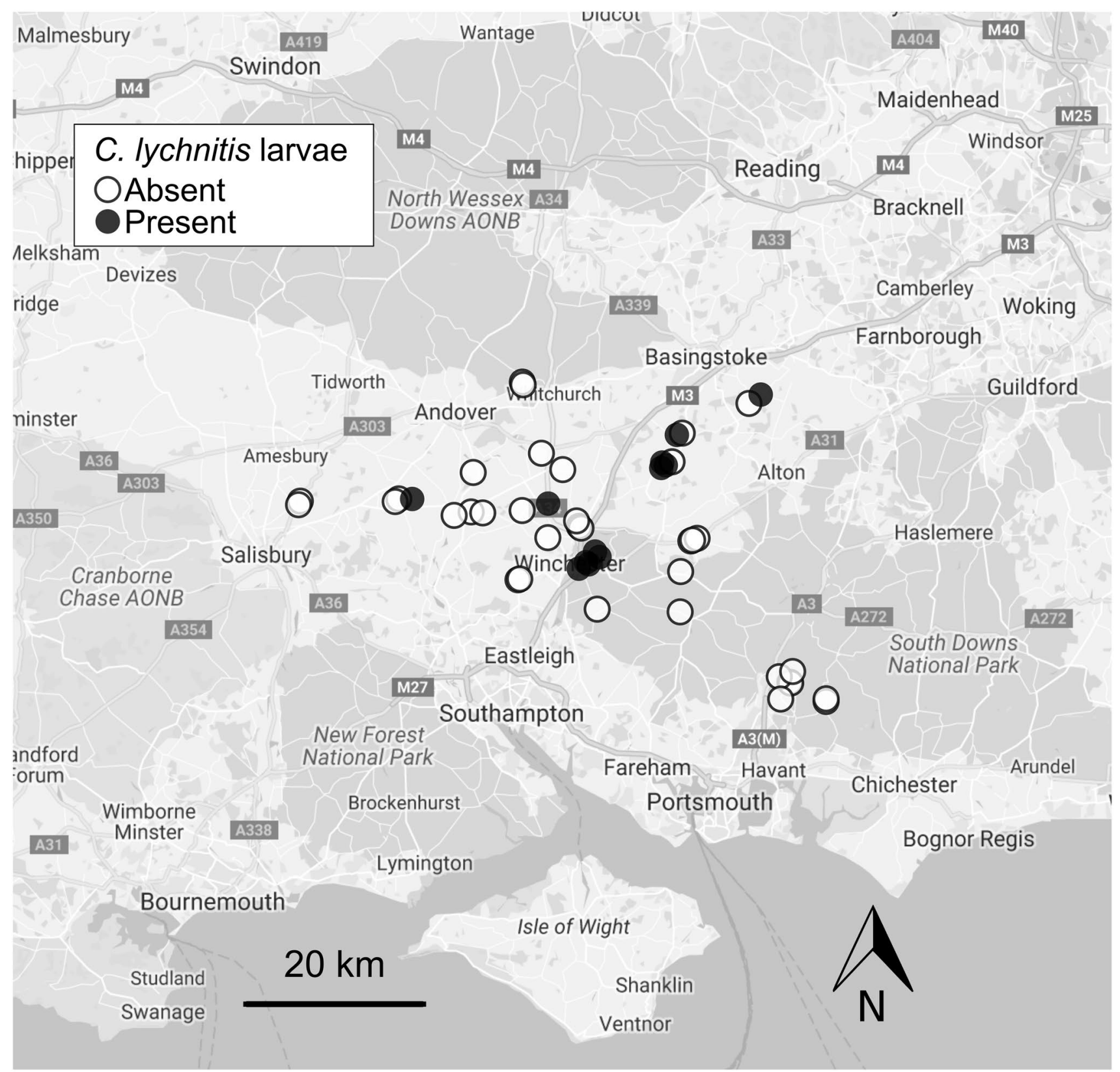

Fig. 2 Patches recorded in the study came from the southern UK population of $C$. lychnitis, centred around Winchester, Hampshire, UK. Surveyed patches occupied by larvae of C. lychnitis are shown as black circles, unoccupied patches as white circles. Map data ${ }^{\odot}$ Google 2017

documented for moths (but see Ravenscroft and Young 1996; Menéndez and Thomas 2000). The importance of host plant abundance as a predictor of patch occupancy is consistent with previous studies emphasising the requirements of immature stages (Bourn and Thomas 2002). The results suggest that conservation approaches typically applied to butterflies may be appropriate more widely for Lepidoptera, including both diurnal and nocturnal species, living in fragmented landscapes.

The results are consistent with isolation-dependent recolonisation rates and area-dependent extinction rates, with both dispersal and demography influencing occupancy (Thomas and Kunin 1999). Some tetrads have records of the adult moth only (including a single record over $40 \mathrm{~km}$ from known larval colonies), and while it seems likely that many larval sites go unrecorded, this is suggestive of high mobility. High dispersal is important to metapopulation dynamics as it facilitates recolonisation of patches. Equally, extinction of local populations of $C$. lychnitis is more likely in smaller patches of $V$. nigrum where resources are limited, making them more vulnerable to environmental or demographic stochasticity. 
Table 1 Summary of analyses testing for variation in Cucullia lychnitis larval occupancy and abundance and Cionus nigritarsis density attributable to a range of ecological variables

\begin{tabular}{|c|c|c|c|c|c|c|}
\hline Unit of replication & Dependent variables & Model structures & Independent variables & $\begin{array}{l}\text { Effect size } \\
\text { (standard } \\
\text { error) }\end{array}$ & LRT $\chi^{2}$ & $P$ \\
\hline \multirow[t]{2}{*}{ Patch (all) } & $\begin{array}{l}\text { Patch occupancy by } C \text {. lychnitis } \\
\text { larvae }\end{array}$ & Binomial GLM & Isolation (mean $\mathrm{NN}$ distance) & $-0.82(0.31)$ & 11.15 & $<0.001$ \\
\hline & & & Patch size (no. flower spikes) & $0.08(0.02)$ & 22.76 & $<0.001$ \\
\hline \multirow[t]{4}{*}{ Patch (occupied) } & $\begin{array}{l}\text { Abundance of } C \text {. lychnitis larvae at } \\
\text { occupied patches }\end{array}$ & Poisson GLM & Isolation (mean $\mathrm{NN}$ distance) & $0.17(0.08)$ & 4.97 & 0.026 \\
\hline & & & C. nigritarsis density & $-1.71(0.63)$ & 47.11 & $<0.001$ \\
\hline & As above (outlier removed) & Poisson GLM & Isolation (mean $\mathrm{NN}$ distance) & $1.81(0.93)$ & 4.00 & 0.045 \\
\hline & & & C. nigritarsis density & $-4.07(1.49)$ & 44.53 & $<0.001$ \\
\hline \multirow[t]{2}{*}{ Patch (all) } & $\begin{array}{l}\text { Density of } C \text {. nigritarsis larvae at } \\
\text { patches }\end{array}$ & Ordinal GLM & Isolation (mean $\mathrm{NN}$ distance) & $-0.28(0.13)$ & 4.56 & 0.033 \\
\hline & & & Patch size (no. flower spikes) & $0.03(0.01)$ & 15.49 & $<0.001$ \\
\hline \multirow{2}{*}{$\begin{array}{l}\text { Plant (patches } \\
\text { with abundant } C \text {. } \\
\text { lychnitis) }\end{array}$} & $\begin{array}{l}\text { Occupancy of plants by C. lychnitis } \\
\text { larvae }\end{array}$ & Binomial GLMM & Plant height & $0.02(0.01)$ & 7.05 & 0.008 \\
\hline & & & No. flower spikes & $0.68(0.12)$ & 54.76 & $<0.001$ \\
\hline
\end{tabular}

Independent variables shown are those retained in the final model for each dependent variable. Significance of variables was tested with a likelihood ratio test

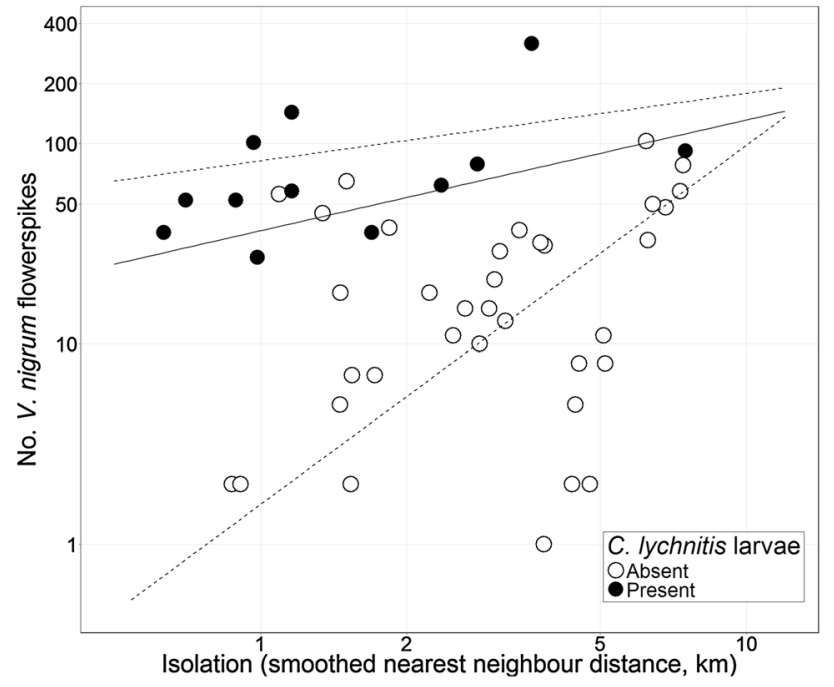

Fig. 3 The occupancy of patches by larvae of C. lychnitis is affected by patch size and isolation. Points show patches recorded in the study; black circles indicate larvae of $C$. lychnitis were present. Model-predicted probability of larval occupancy is $>50 \%$ for patches above the solid line (dashed lines show $95 \%$ confidence interval)

Comparing between occupied patches, abundance of $C$. lychnitis larvae was not related to abundance of $V$. nigrum but instead was affected by density of larvae of the weevil $C$. nigritarsis. Eggs of $C$. nigritarsis are laid directly on the flower buds of V. nigrum (Sõber et al. 2010), whereas C. lychnitis eggs are laid on the leaves (Heath and Emmet 1983). High densities of $C$. nigritarsis were observed

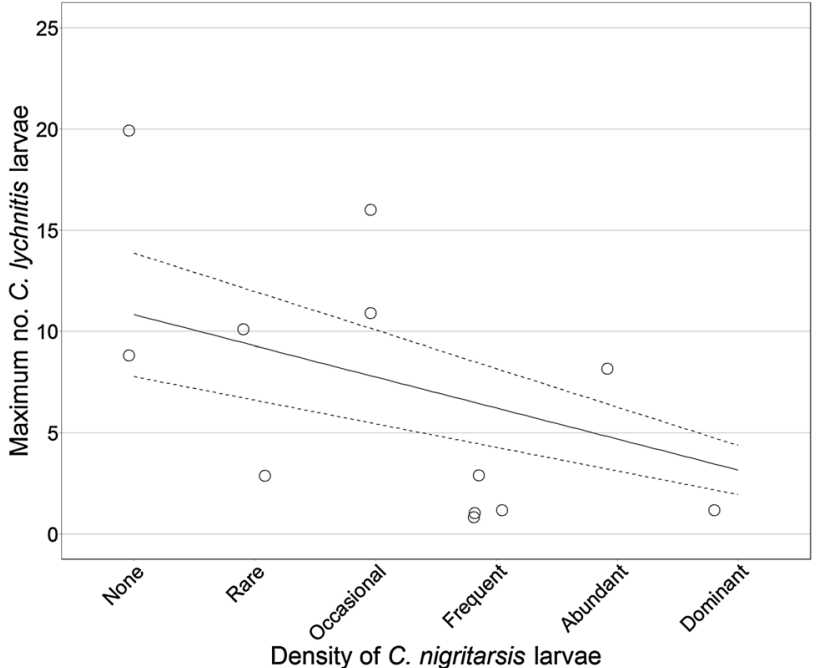

Fig. 4 The maximum abundance of $C$. lychnitis larvae at occupied patches is influenced by the density of larvae of competitor $C$. nigritarsis. Points show C. lychnitis larval abundance at occupied patches recorded in the study. A line-of-best-fit is plotted through modelpredicted larval abundances at each level of $C$. nigritarsis density (dashed lines show standard error)

throughout the study to cause severe feeding damage to $V$. nigrum flower spikes from around 14 days before the first larvae of $C$. lychnitis were recorded, reducing the food resource available to the moth larvae. As $C$. lychnitis larvae were not readily located until the third instar (due to small size and lack of conspicuousness), it is possible that the 


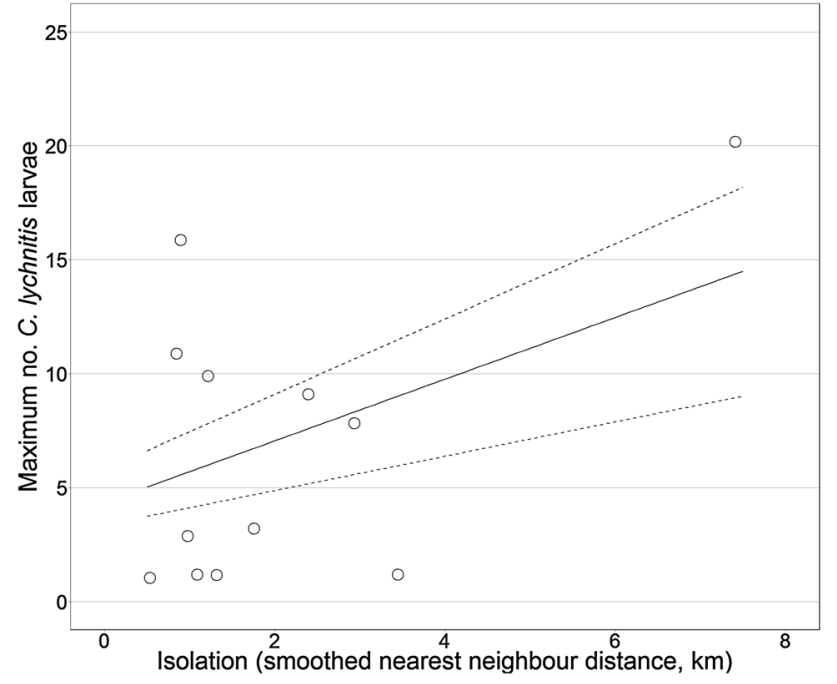

Fig. 5 The maximum abundance of $C$. lychnitis larvae at occupied sites is influenced by patch isolation. Points show C. lychnitis larval abundance at occupied patches recorded in the study. Solid line shows model-predicted larval abundance (dashed lines show standard error)

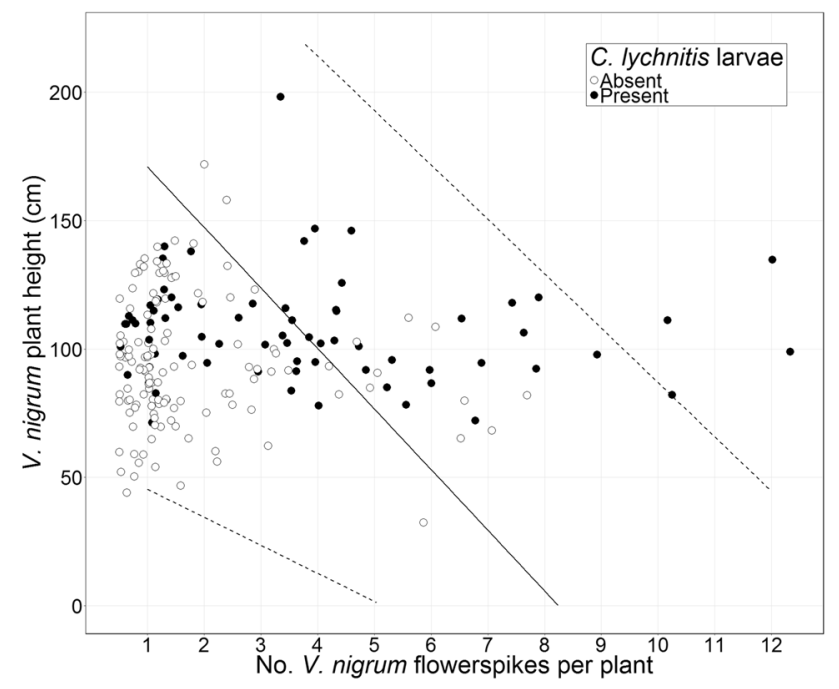

Fig. 6 The occupancy of individual $V$. nigrum plants by $C$. lychnitis within occupied patches is influenced by plant height and number of flower spikes. Points show plants recorded in the study; black circles indicate larvae of $C$. lychnitis were present. Model-predicted probability of larval occupancy is $>50 \%$ for patches above the solid line (dashed lines show 95\% confidence interval)

observed pattern can be attributed to variation in survival rates of $C$. lychnitis larvae during the early instars, caused by varying levels of interspecific competition for food with C. nigritarsis larvae.

Surprisingly, larvae of $C$. lychnitis, where found, were more abundant at more isolated patches. One possible explanation is a tendency for female $C$. lychnitis to lay more eggs on a plant if they have not recently located any others; this strategy has been recorded in other species of Lepidoptera (Mackay and Singer 1982). Alternatively, density of $C$. nigritarsis across patches was affected by the same variables as patch occupancy by $C$. lychnitis, patch size and isolation, potentially explaining this pattern. Larvae of $C$. lychnitis in less isolated patches may experience elevated competition from $C$. nigritarsis larvae, but further study is needed to establish whether competition from $C$. nigritarsis can influence $C$. lychnitis population dynamics. However, $V$. nigrum seed set and pollinator visitation rate both decrease with increased intensity of florivory by $C$. nigritarsis (Sõber et al. 2009). As C. lychnitis larvae primarily feed on developing seed heads (i.e., fertilized flowers), it is therefore probable that $C$. nigritarsis presence reduces the available food resource for $C$. lychnitis, providing a mechanism for such competitive exclusion.

Cionus nigritarsis is also rare in the UK, recorded in only 17 tetrads since 2000 (although it is unlikely to have received the same survey effort as $C$. lychnitis and may therefore be under-recorded) and, as a specialist on $V$. nigrum (Morris 2002), may also have been impacted by the decreasing range of $V$. nigrum. The abundance of $C$. nigritarsis increases with $V$. nigrum patch size (Sõber et al. 2009), but the dispersal abilities of $C$. nigritarsis adults and the influence of patch isolation on its abundance are unknown. The weevil is able to fly (Sõber et al. 2010), but if it is less mobile than $C$. lychnitis the moth would be more likely to locate and capitalise on isolated patches than the weevil. Such a difference in dispersal abilities could facilitate coexistence of these competing species if colonisation-competition trade-offs generate a spatial refuge in isolated patches (Tilman 1994). However, in our models, the effect of patch isolation was greater for $C$. lychnitis occupancy than for $C$. nigritarsis density, which does not support this hypothesis (Table 1). The existence of such a mechanism would warrant further investigation; if operating then there may be important implications for the conservation of isolated patches and for the consequences of further habitat destruction (Nee and May 1992).

Occupancy of individual V. nigrum plants by $C$. lychnitis within occupied patches was affected by both plant height and number of flower spikes, with larvae more likely to occupy taller plants with more flower spikes. As C. lychnitis larvae feed directly upon the flower spikes, both taller plants and those with more flower spikes provide a greater resource to larvae. Both of these variables should correlate with increasing plant age; in particular, multiple flower spikes are only expected to occur on plants in their second or subsequent flowering season. Therefore, patches that are present over a number of years may contain older, larger $V$. nigrum plants and thus provide greater larval resources for C. lychnitis. Plant age might also plausibly correlate with 
total leaf area, which would provide a mechanism for adult female $C$. lychnitis to select older, larger plants when laying eggs, before flower spikes have grown. On repeat visits to occupied patches, larvae were never observed to have moved between flower spikes, suggesting plant-level occupancy is determined at the egg-laying stage.

These findings suggest several actions that may aid the conservation of $C$. lychnitis. The relationship between patch occupancy and both abundance of $V$. nigrum and proximity to other patches indicates that conservation efforts should concentrate on large patches of $V$. nigrum located close to other patches. A number of patches located during the survey were very small, with 7 patches having 5 or fewer flower spikes of $V$. nigrum present; however, the smallest occupied patch had 27 flower spikes, although $C$. lychnitis larvae have been recorded at smaller patches and even single, isolated host plants in subsequent surveys (MSP, unpublished data). Thus, increasing the size (through planting or ground disturbance followed by seeding of $V$. nigrum) of small patches close to occupied patches may provide opportunities for dispersal and establishment of new local populations. However, the parallel preference of $C$. nigritarsis for larger, less isolated patches of $V$. nigrum indicates that a balance between large patch size and low weevil density may be of most benefit to $C$. lychnitis. Finally, the apparent preference within occupied patches for plants that have been flowering for more than 1 year highlights the potential importance of ensuring that existing patches persist, although it is not clear from this study whether patch persistence affects patch occupancy or larval abundance. As V. nigrum is a ruderal species, regular if infrequent disturbance of patches may be necessary to prevent ecological succession from proceeding; however, it is clearly important that such disturbance, especially in the form of road verge mowing, should not take place during the flowering period of $V$. nigrum, to ensure that larvae of C. lychnitis are able to complete development and pupate safely in the soil.

While clear patterns emerged from our data, a larger data set across a wider set of $C$. lychnitis populations would be valuable. Weather conditions were poor during the flight period of $C$. lychnitis prior to the survey work, with prolonged and heavy rainfall. This may explain why both the abundance of $C$. lychnitis larvae and the number of occupied patches were lower than had been documented in previous surveys of the same sites. To increase the area that could be searched, we limited the survey to accessible road verges, meaning that data for some occupied patches was not included. In combination, these factors mean that sample sizes for some aspects of the study were small; in particular, analyses of variables affecting variations in abundance of $C$. lychnitis larvae between patches were based on just 12 data points. Furthermore, C. lychnitis exists in two distinct populations in the UK, of which this study focussed exclusively on the southern, Hampshire population. We cannot assume that the same variables are important in influencing the incidence and abundance of $C$. lychnitis throughout its range.

A valuable area for future study would be the factors that determine presence and abundance of $V$. nigrum itself. This species has been previously shown to suffer reduced visitation by pollinators (primarily bumblebees) under infestation by $C$. nigritarsis, especially in large patches (Sõber et al. 2009, 2010), although a separate study found no evidence for pollination limitation (Dauber et al. 2010). Nevertheless, these studies address success of V. nigrum where it is already established, and so the reason why patches exist in some places but are absent from others is also unclear. It is likely that the ruderal nature of the species has some effect: seeds germinate more successfully and produce faster-growing shoots on bare soil than in even short swards, and may fail entirely in tall swards (Fenner 1978). A fuller understanding of the ecology of this plant would facilitate efforts to increase the size, and reduce the isolation, of $C$. lychnitis local populations.

\section{Conclusions}

This study has identified a number of ecological variables which appear to have an effect upon the Striped Lychnis moth $C$. lychnitis. These include both isolation and size of patches of the host plant $V$. nigrum, abundance of a potentially competitive species of weevil, $C$. nigritarsis, and possibly persistence of patches of $V$. nigrum for multiple consecutive breeding seasons. These findings should be of use in guiding policy for the conservation of C. lychnitis, while areas of uncertainty and priorities for future work have been identified.

Acknowledgements We thank L. Hill and the National Moth Recording Scheme for providing historical records and an updated distribution map for $C$. lychnitis, and J. Parsons for sharing sightings of $C$. lychnitis. We are grateful to two knowledgeable anonymous reviewers, whose comments helped improve the manuscript.

Open Access This article is distributed under the terms of the Creative Commons Attribution 4.0 International License (http:// creativecommons.org/licenses/by/4.0/), which permits unrestricted use, distribution, and reproduction in any medium, provided you give appropriate credit to the original author(s) and the source, provide a link to the Creative Commons license, and indicate if changes were made. 


\section{References}

Bates D, Maechler M, Bolker B, Walker S (2015) Fitting linear mixed-effects models using lme4. J Stat Softw 67:1-48

Bourn NAD, Thomas JA (2002) The challenge of conserving grassland insects at the margins of their range in Europe. Biol Conserv 104:285-292

Dauber J, Biesmeijer JC, Gabriel D, Kunin WE, Lamborn E, Meyer B, Nielsen A, Potts SG, Roberts SPM, Sõber V, Settele J, Steffan-Dewenter I, Stout JC, Teder T, Tscheulin T, Vivarelli D, Petanidou T (2010) Effects of patch size and density on flower visitation and seed set of wild plants: a pan-European approach. J Ecol 98:188-196

Fenner M (1978) A comparison of the abilities of colonizers and closed-turf species to establish from seed in artificial swards. J Ecol 66:953-963

Fowler J, Cohen L, Jarvis P (2013) Practical statistics for field biology. Wiley, Chichester

Hall P (2010) The 2010 Striped Lychnis (Shargacucullia lychnitis) report for Buckinghamshire. Unpublished report

Hanski I, Kuussaari M, Nieminen M (1994) Metapopulation structure and migration in the butterfly Melitaea cinxia. Ecology 75:747-762

Heath J, Emmet AM (1983) Moths and butterflies of Great Britain and Ireland, vol 10 (Noctuidae-Cuculliinae to Hypeninae, and Agaristidae). Harley Books, Colchester

Hill JK, Thomas CD, Lewis OT (1996) Effects of habitat patch size and isolation on dispersal by Hesperia comma butterflies: implications for metapopulation structure. J Anim Ecol 65:725-735

Hoare D, Thomas K (2006) The Striped Lychnis Shargacucullia lychnitis (Rambur, 1833): larval survey 2003. Butterfly Conservation Report No. S06-05

Kahle D, Wickham H (2013) ggmap: spatial visualization with ggplot2. R J 5:144-161

Mackay DA, Singer MC (1982) The basis of an apparent preference for isolated host plants by ovipositing Euptychia libye butterflies. Ecol Entomol 7:299-303

Menéndez R, Thomas CD (2000) Metapopulation structure depends on spatial scale in the host-specific moth Wheeleria spilodactylus (Lepidoptera: Pterophoridae). J Anim Ecol 69:935-951

Morris MG (2002) True weevils (Part I): family Curculionidae, subfamilies Raymondionyminae to Smicronychinae. Royal Entomological Society of London, London

Natural Environment and Rural Communities Act 2006, Section 41. The Stationery Office, London
Nee S, May RM (1992) Dynamics of metapopulations: habitat destruction and competitive coexistence. J Anim Ecol 61:37-40

Preston CD, Pearman D, Dines TD (2002) New atlas of the British and Irish flora: an atlas of the vascular plants of Britain, Ireland, the Isle of Man and the Channel Islands. Oxford University Press, Oxford

R Core Team (2016) R: a language and environment for statistical computing, Version 3.3.2. R Foundation for Statistical Computing, Vienna. https://www.R-project.org/

Ravenscroft NOM, Young MR (1996) Habitat specificity, restricted range and metapopulation persistence of the Slender Scotch Burnet moth Zygaena loti in Western Scotland. J Appl Ecol 33:993-1000

Rosenthal AD (2011) Striped Lychnis Shargacucullia lychnitis (Rambur, 1833): UK distribution and larval surveys 2008 to 2010. Butterfly Conservation Report No. S11-19

Sõber V, Teder T, Moora M (2009) Contrasting effects of plant population size on florivory and pollination. Basic Appl Ecol 110:737-744

Sõber V, Moora M, Teder T (2010) Florivores decrease pollinator visitation in a self-incompatible plant. Basic Appl Ecol 11:669-675

Stewart KEJ, Bourn NAD, Thomas JA (2001) An evaluation of three quick methods commonly used to assess sward height in ecology. J Appl Ecol 38:1148-1154

Thomas CD, Kunin WE (1999) The spatial structure of populations. J Anim Ecol 68:647-657

Thomas CD, Thomas JA, Warren MS (1992) Distributions of occupied and vacant butterfly habitats in fragmented landscapes. Oecologia 92:563-567

Thomas JA, Simcox DJ, Hovestadt T (2010) Evidence based conservation of butterflies. J Insect Conserv 15:241-258

Tilman D (1994) Competition and biodiversity in spatially structured habitats. Ecology 75:2-16

Warren MS, Bourn N, Brereton T, Fox R, Middlebrook I, Parsons MS (2007) What have red lists done for us? The values and limitations of protected species listing for invertebrates. In: Insect conservation biology: proceedings of the Royal Entomological Society's 23rd symposium. CAB International, Wallingford, p 76-91

Wickham H (2009) ggplot2: elegant graphics for data analysis. Springer, New York

Winfree R, Dushoff J, Crone EE, Schultz CB, Budny RV, Williams NM, Kremen C (2005) Testing simple indices of habitat proximity. Am Nat 165:707-717 